\title{
Consistency of Maturity Rate for Milk Yield Across Countries and Generations
}

\author{
H. D. Norman, ${ }^{\star 1}$ J. R. Wright, ${ }^{\star}$ R. L. Powell, ${ }^{\star}$ P. M. VanRaden, ${ }^{*}$ F. Miglior, †‡ and G. de Jong§ \\ *Animal Improvement Programs Laboratory, Agricultural Research Service, USDA, Beltsville, MD 20705-2350 \\ †Dairy and Swine Research and Development Centre, Agriculture and Agri-Food Canada, Sherbrooke, Quebec, Canada, J1M $1 Z 3$ \\ $\ddagger$ Canadian Dairy Network, Guelph, Ontario, Canada, N1G T42 \\ $\S N e d e r l a n d s$ Rundvee Syndicaat (NRS), Arnhem, the Netherlands
}

\section{ABSTRACT}

Differences among bulls in maturity rate of their daughters for milk yield were investigated. Milk records for US Holsteins with first-parity calving dates between 1960 and 1998 were used to calculate 3 evaluations for bulls based on daughter records from parity 1 , parities 1 and 2 , and parities 1,2 , and 3 . The 3 evaluations were used to estimate parity-specific evaluations for parities 2 and 3. Maturity rate of Holstein bull daughters in Canada and the Netherlands was compared with that for daughters of the same bulls in the United States by using official November 2004 Canadian and August 2005 Dutch parity-specific evaluations. For bulls with $\geq 500$ first-parity daughters, correlations among parity-specific evaluations within country and birth year of bull were 0.88 between parities 1 and 2, 0.84 between parities 1 and 3, and 0.96 between parities 2 and 3 for the United States; 0.90, 0.86, and 0.97, respectively, for Canada; and 0.92, 0.89, and 0.98, respectively, for the Netherlands. Correlations between Canada and the United States for within-country differences between evaluations for parities 1 and 2 were 0.72 for bulls with $\geq 50$ first-parity daughters and 0.89 for bulls with $\geq 500$ first-parity daughters; corresponding correlations between the Netherlands and the United States were 0.66 and 0.82 . Correlations between countries for differences between evaluations for parities 1 and 3 were slightly less, and corresponding correlations between evaluations for parities 2 and 3 were still lower. To establish whether differences between parity-specific evaluations were genetic, comparisons were made across a generation. Coefficients for regression of son on sire within country and birth years of sire and son for parity-specific evaluations and differences between parity-specific evaluations ranged from 0.35 to 0.53 , with standard errors of $\leq 0.04$. Differences in

Received December 22, 2006.

Accepted April 20, 2007.

${ }^{1}$ Corresponding author: dnorman@aipl.arsusda.gov maturity rate of bull daughters were quite consistent across country, and those differences were transmitted to the sons' daughters. Modeling to account for maturity differences should increase the accuracy of US evaluations and reduce fluctuation between evaluations, especially for bulls with daughters that deviate substantially from the population mean for maturity rate for milk yield.

Key words: genetic evaluation, maturity rate, milk yield, parity

\section{INTRODUCTION}

Cassell et al. (1983) demonstrated that Holstein bulls differed in the maturity rate of their daughters for milk yield. They estimated that the standard deviation of differences between bull evaluations for milk yield based on first and later parities was 59\% as large as the standard deviation of genetic differences among bulls. Strandberg (1991) summarized literature estimates of genetic correlations between parities for milk yield and reported means of 0.78 between parities 1 and 2, 0.77 between parities 1 and 3, and 0.89 between parities 2 and 3 for 7 dairy breeds, with estimates for all 3 parities. The means for corresponding correlations in the literature since 1988 cited by Norman et al. (2005) for all breeds were $0.89,0.85$, and 0.94 . Abdallah and McDaniel (2002) examined USDA evaluations from different evaluation dates for Holstein progeny-test bulls to study changes in yield PTA from evaluations based on daughter records from parity 1 to evaluations based on all daughter records. They concluded that the evaluation model probably needs to include correlated effects for first and later parities to reduce evaluation instability across time.

Throughout progeny testing for a bull, the percentage of daughters with later-parity records increases. In contrast, information that contributes to evaluations for bulls that start to add second-crop daughters shifts from later- to first-parity records. As bulls continue to add second-crop daughters, information from later- 
parity records typically increases again. Norman et al. (2004) documented the extent to which Holstein bull PTA differed according to whether records from parities 1,2 , or 3 were included. Evaluations tailored by parity provided differences that appeared to result from differing maturity rates of bull daughters for milk yield. Norman et al. (2004) reported that some bulls had PTA for third-parity milk yield that was $550 \mathrm{~kg}$ higher or $600 \mathrm{~kg}$ lower than PTA for parity 1. The same study showed that oscillations in PTA milk across evaluations were partly attributable to bulls with daughters that appeared to deviate from the typical response to aging. The standard deviation of PTA change was half as large when evaluations were tailored for specific parities as when evaluations included all records through parity 5 as a single trait.

As of November 2006, 14 countries (Austria, Belgium, Canada, the Czech Republic, Denmark, Estonia, Finland, Germany, Italy, Luxembourg, the Netherlands, Poland, Sweden, and the United Kingdom) provided Holstein bull evaluations that include genetic effects by parity to consider differences in maturity rate to the International Bull Evaluation Service (Interbull, 2006a). In Canada (Schaeffer et al., 2000) and the Netherlands (De Roos et al., 2001), genetic evaluations are calculated with a multitrait, random-regression, testday animal model. Parity-specific evaluations are made available to Canadian producers (Schaeffer et al., 2000). In the Netherlands, breeding values for maturity rate are used in calculating INET, the Dutch net profit index for milk production (NRS, 2005). In contrast, the United States and several other countries calculate official evaluations with a single-trait repeatability model (Interbull, 2006a). Sullivan (2000) compared approaches for modeling differences in maturity rate across countries and concluded that precise correlation estimates would be critical for implementation. Attempts by Jorjani (2006) to use a multitrait model to estimate genetic correlations among 28 female fertility traits from 14 countries for international genetic evaluation resulted in fluctuations among correlations that could be as large as the correlation estimates, and the use of the multitrait model was not recommended until issues related to the reliability of correlation estimates could be resolved.

If differences in the maturity rate of daughters affect the ranking of bulls across time, modeling for differences in maturity rate should produce more stable evaluations, thus raising breeder confidence in addition to improving selection decisions. However, any number of environmental effects could be associated with the daughters of individual bulls and result in the appearance that bulls transmit differently for maturity rate than they actually do. A random regression on parity was developed and tested with US Jersey evaluations, but predictions of future PTA were not more accurate (Wiggans and VanRaden, 2004).

To ascertain whether differences observed between parity-specific evaluations are genetic, the relationship between those differences should be examined among sires and sons to determine the extent to which differences are transmitted. If maturity rate were consistent for the same bulls across countries and were transmitted across generations, any suspicion that the apparent differences were caused by any unknown environmental effects would be virtually eliminated. The primary objective of this study was to determine whether differences observed among bulls in the maturity rate of their daughters were consistent across countries and were genetic (i.e., transmitted across generations).

\section{MATERIALS AND METHODS}

\section{Bull Evaluations by Parity}

United States. Norman et al. (2005) used Holstein lactation records in the national database of USDA's Animal Improvement Programs Laboratory (Beltsville, MD) to calculate 3 parity-specific genetic evaluations for cow sires. Cows were required to have a calving date between 1960 and 1998 for parity 1. Standardized milk yield through October 8, 2003, was evaluated; milk records were standardized for calving age, calving month, previous days open, and daily milking frequency (Animal Improvement Programs Laboratory, 2005). Lactation credits (including those from terminated or in-progress records) were projected to $305 \mathrm{~d}$ from test-day data with the best prediction method of VanRaden (1997). Only milk records from the first 3 parities of a cow in her first herd were included, and all cows with records from parities 2 and 3 were required to have lactation records from preceding parities.

Parity-specific PTA for milk yield in this study were those calculated by Norman et al. (2005), which were based on 3 tailored evaluations for each bull from current USDA-DHIA animal model methodology (Wiggans and VanRaden, 1989) and selected records: 1) PTA based on records from parity 1 (USA $\left.\left.\mathbf{U}_{1}\right), 2\right)$ PTA based on records from parities 1 and 2 (USA $\mathbf{U S A}_{\mathbf{1}, 2}$ ), and 3) PTA based on records from parities 1,2 , and 3 (USA $\mathbf{U S A}_{\mathbf{1 , 2}, \mathbf{3}}$ ). Because $\mathrm{USA}_{1,2}$ and $\mathrm{USA}_{1,2,3}$ were based on cumulative parities, they and $\mathrm{USA}_{1}$ were used to derive the direct contributions from parity $2\left(\mathbf{U S A}_{\mathbf{2}}\right.$ ) and parity 3 ( $\mathbf{U S A}_{\mathbf{3}}$ ) by weighting for the number of records for each parity. If PTA had been calculated with the same evaluation procedure but using only records from the parity to be evaluated (e.g., records from parity 3 without considering records from parities 1 and 2), $\mathrm{USA}_{2}$ and $\mathrm{USA}_{3}$ would have been biased because cows with high milk 
Table 1. Numbers of Holstein bulls by country of evaluation and by numbers of first-parity daughters

\begin{tabular}{lcr}
\hline & \multicolumn{2}{c}{ Bulls (n) } \\
\cline { 2 - 3 } Country of evaluation & $\geq 50$ daughters & $\geq 500$ daughters \\
\hline Canada & 4,991 & 373 \\
The Netherlands & 4,773 & 303 \\
United States & 16,605 & 2,850 \\
Canada and the Netherlands & 227 & 51 \\
Canada and the United States & 557 & 131 \\
The Netherlands and the United States & 536 & 93 \\
\hline
\end{tabular}

yield during early parities are less likely to be culled (Keown et al., 1976; Norman et al., 2007). Including all records on which female culling was based eliminates bias from evaluations if appropriate methods have been used to account for repeatability and age adjustment (Henderson et al., 1959).

The following relationships among tailored evaluations were assumed:

$$
\mathrm{USA}_{1,2}=\left(\mathrm{n}_{1} \mathrm{USA}_{1}+\mathrm{n}_{2} \mathrm{USA}_{2}\right) /\left(\mathrm{n}_{1}+\mathrm{n}_{2}\right)
$$

and

$$
\begin{gathered}
\mathrm{USA}_{1,2,3}= \\
\left(\mathrm{n}_{1} \mathrm{USA}_{1}+\mathrm{n}_{2} \mathrm{USA}_{2}+\mathrm{n}_{3} \mathrm{USA}_{3}\right) /\left(\mathrm{n}_{1}+\mathrm{n}_{2}+\mathrm{n}_{3}\right),
\end{gathered}
$$

where $\mathrm{n}_{1}, \mathrm{n}_{2}$, and $\mathrm{n}_{3}$ are the number of bull daughters with records for parities 1,2 , and 3 , respectively. Parityspecific contributions were derived by

$$
\mathrm{USA}_{2}=\left[\left(\mathrm{n}_{1}+\mathrm{n}_{2}\right) \mathrm{USA}_{1,2}-\mathrm{n}_{1} \mathrm{USA}_{1}\right] / \mathrm{n}_{2}
$$

and

$$
\begin{gathered}
\mathrm{USA}_{3}= \\
{\left[\left(\mathrm{n}_{1}+\mathrm{n}_{2}+\mathrm{n}_{3}\right) \mathrm{USA}_{1,2,3}-\mathrm{n}_{1} \mathrm{USA}_{1}-\mathrm{n}_{2} \mathrm{USA}_{2}\right] / \mathrm{n}_{3} .}
\end{gathered}
$$

To illustrate how bulls differ in apparent maturity rate, 2 were selected that had opposite extremes for parity-specific PTA based on age-adjusted yield of many daughters. Hanoverhill Stardom had $\mathrm{PTA}_{1}, \mathrm{PTA}_{2}$, and $\mathrm{PTA}_{3}$ of 170,426 , and $544 \mathrm{~kg}$, respectively, based on 1,477 daughters. Differences of $256 \mathrm{~kg}$ for $\mathrm{PTA}_{2}-\mathrm{PTA}_{1}$ and $374 \mathrm{~kg}$ for $\mathrm{PTA}_{3}-\mathrm{PTA}_{1}$ indicated that Stardom's daughters had much higher yields during second and third lactations than during first. In contrast, Maizefield Bellwood-ET had PTA $1, \mathrm{PTA}_{2}$, and $\mathrm{PTA}_{3}$ of 1,369, 995, and $985 \mathrm{~kg}$, respectively, based on 6,997 daughters, with differences of $-374 \mathrm{~kg}$ for $\mathrm{PTA}_{2}-\mathrm{PTA}_{1}$ and $-384 \mathrm{~kg}$ for $\mathrm{PTA}_{3}-\mathrm{PTA}_{1}$. Compared with daughters of bulls that are genetically average for maturity rate, a Stardom daughter would be expected to produce 374 kg more milk during third lactation, whereas a Bellwood daughter would be expected to produce $384 \mathrm{~kg}$ less, a difference of $758 \mathrm{~kg}$ between Stardom and Bellwood daughters. In spite of the lower yield of Belwood daughters for later parities relative to first, Belwood daughters still outproduced Stardom daughters, even for parity 3 .

Canada and the Netherlands. Canadian Holstein evaluations were parity-specific EBV for milk yield for parities 1,2, and 3 that were calculated from only Canadian records with a test-day model (Schaeffer et al., 2000) and released in November 2004 by the Canadian Dairy Network (Guelph, Ontario, Canada). Dutch Hol-

Table 2. Correlations within birth year of Holstein bulls between parity-specific evaluations for milk yield (bulls with $\geq 50$ daughters above the diagonal; bulls with $\geq 500$ daughters below the diagonal) among Canada, the Netherlands, and the United States

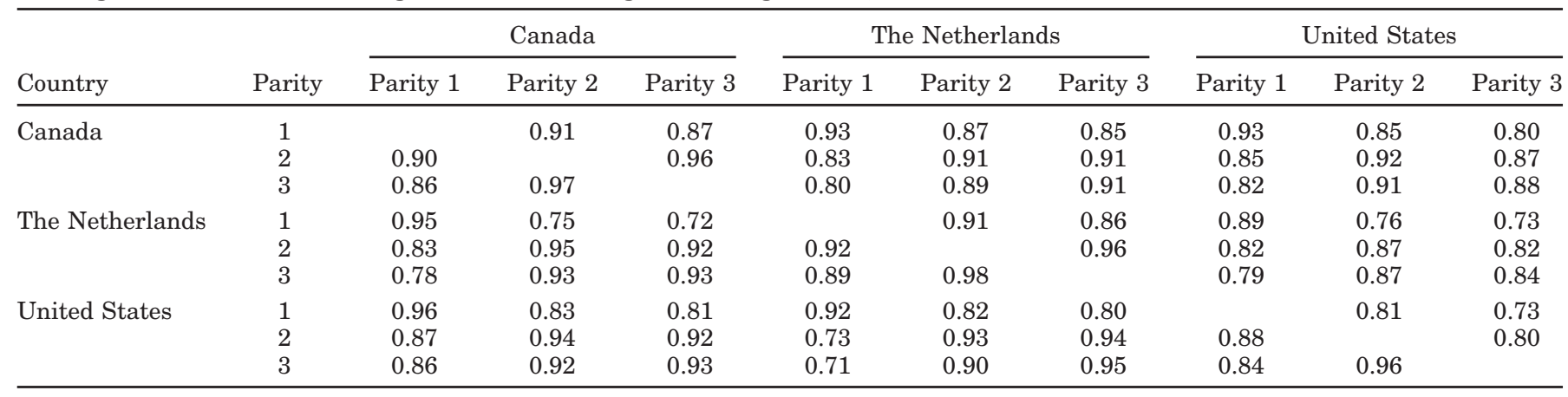




\section{A) Canada}

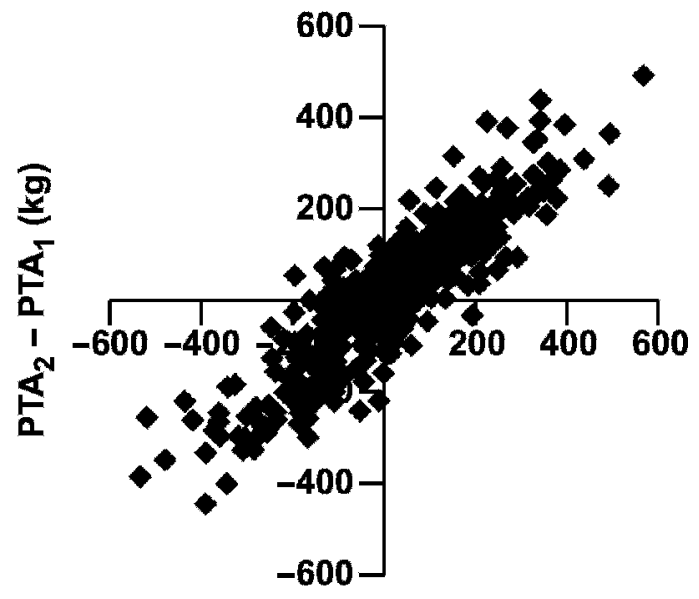

B) The Netherlands

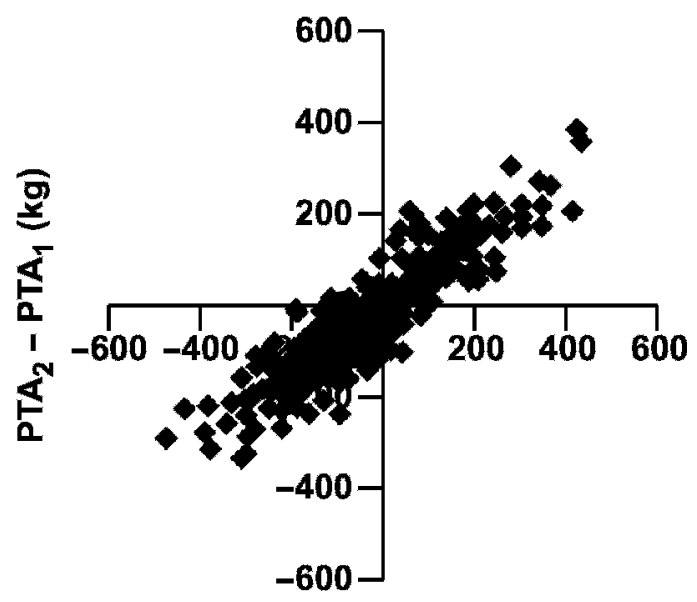

C) United States

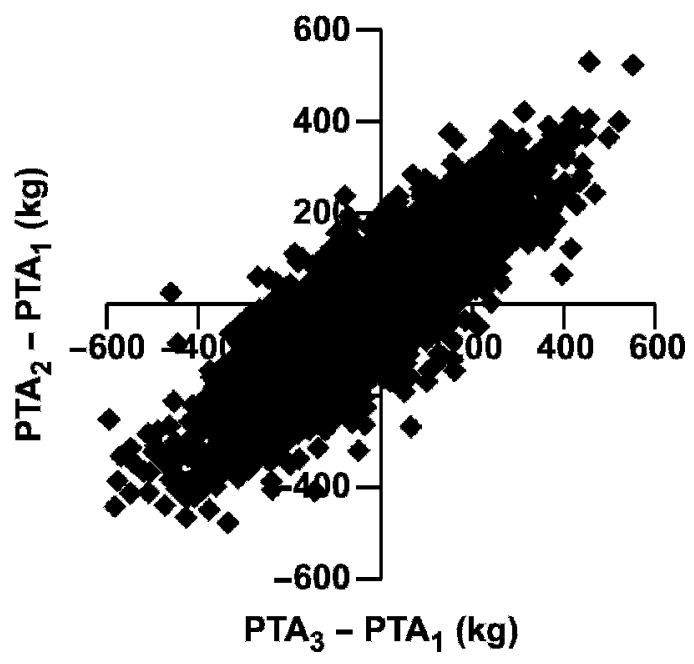

Figure 1. Scatter plots of differences between parity-specific PTA for bulls with $\geq 500$ daughters in A) Canada, B) the Netherlands, and C) the United States. stein evaluations also were parity-specific EBV for milk yield for the first 3 parities that were calculated from only Dutch records with a test-day model (De Roos et al., 2001); they were released in August 2005 by the NRS (Arnhem, the Netherlands). Both Canadian and Dutch evaluations were expressed as cumulative 305-d EBV that had been standardized to a common variance (Schaeffer et al., 2000; De Roos et al., 2001). Canadian and Dutch evaluations included information only from bull daughters within country to avoid part-whole relationships that would be created if Interbull evaluations were included.

\section{Parity Relationships Within and Across Countries}

Correlations within and across countries were calculated between parity-specific evaluations within birth year for bulls with $\geq 50$ or $\geq 500$ first-parity daughters. Because bulls were selected based on the number of first-parity daughters, Canadian and Dutch bulls also were restricted based on the number of daughter test days (Canada) and the number of daughter records (the Netherlands) for successive parities to ensure that bulls had a reasonable number of daughters with second and third lactations. The number of daughter test days or records were required to be at least half as many for parity 2 as for parity 1 and at least one-fourth as many for parity 3 as for parity 1 . The numbers of bulls are shown in Table 1 . Bulls with $\geq 500$ daughters were of particular interest because their true breeding values for milk yield for specific parities should be predicted with great precision. Bulls with evaluations in $>1$ country were of interest because they were likely to reveal some of the effect of evaluation model on estimates of genetic merit.

Differences between parity-specific evaluations within country were calculated. Correlations between countries were calculated for those differences within birth year for bulls with $\geq 50$ or $\geq 500$ daughters.

\section{Maturity Effects Across Generations}

To determine whether observed differences in parityspecific evaluations were transmitted, sire and son evaluations were compared. Regression of son evaluation for milk yield on sire evaluation for milk yield calculated within sire and son birth years was expected to be slightly less than 0.50 . Without ancestor information included in evaluations, the expected regression would be the mean reliability of son evaluations times 0.50 ; because ancestor information was included in evaluations, the expected regression would be slightly higher but still $<0.50$.

For bulls with $\geq 500$ daughters and sons with $\geq 50$ daughters, son evaluations were regressed within coun- 
Table 3. Correlations within birth year of Holstein bulls for differences in parity-specific evaluations for milk yield within country among Canada, the Netherlands, and the United States by number of bull daughters for bulls that were evaluated in both countries

\begin{tabular}{lllc}
\hline \multirow{2}{*}{$\begin{array}{l}\text { Parity-specific } \\
\text { evaluation difference }\end{array}$} & \multicolumn{1}{c}{ Countries } & $\geq 50$ & $\geq 500$ \\
\hline Parity 2 - parity 1 & Canada, the Netherlands & 0.70 & 0.85 \\
& Canada, United States & 0.72 & 0.89 \\
The Netherlands, United States & 0.66 & 0.82 \\
Parity 3 - parity 1 & Canada, the Netherlands & 0.62 & 0.79 \\
& Canada, United States & 0.65 & 0.84 \\
Parity 3 - parity 2 & The Netherlands, United States & 0.61 & 0.83 \\
& Canada, the Netherlands & 0.29 & 0.61 \\
& Canada, United States & 0.20 & 0.55 \\
& The Netherlands, United States & 0.18 & 0.70 \\
\hline
\end{tabular}

try on sire evaluations for parity-specific and official evaluations. Official US evaluations, which include information from the first 5 parities (Animal Improvement Programs Laboratory, 2005), were USDA-DHIA evaluations from August 2005; most bull daughters with information included in parity-specific evaluations had the opportunity to complete 5 lactations. Canadian official overall evaluations were November 2004 means of parity-specific evaluations for the first 3 parities (Schaeffer et al., 2000). Dutch official overall evaluations included August 2005 parity-specific evaluations for the first 3 parities weighted by factors that were primarily based on the distribution of parities but also accounted for the longer time required for later-parity yield to be realized and the higher correlation between yield from parities 2 and 3 and yield from parity 4 and later (NRS, 2005).

Differences between parity-specific evaluations of sons also were regressed within country on corresponding differences for sires. If apparent differences in maturity rate are genetic, regressions coefficients derived from differences between parities also should approach 0.50 .

\section{RESULTS AND DISCUSSION}

\section{Parity Relationships Within and Across Countries}

Correlations within birth year between parity-specific evaluations (Table 2) generally were higher (25 of 36 estimates) for bulls with $\geq 500$ daughters than for those with $\geq 50$ daughters (means of 0.88 and 0.86 , respectively). As expected, within-country correlations were usually higher than across-country correlations (means of 0.89 and 0.86 , respectively), because withincountry parity-specific evaluations often were based on information from the same daughters. Correlations were nearly always higher between parities 2 and 3 than between parities 1 and 2 or 1 and 3. Correlations between parities 2 and 3 ranged from 0.80 to 0.98 within country and from 0.82 to 0.94 across country. In contrast, correlations were always lowest between parities 1 and 3: 0.73 to 0.89 within country and 0.71 to 0.86 across country. Thus, correlations between parities 1 and 2 were nearly always intermediate to the other parity pairs: 0.81 to 0.92 within country and 0.73 to 0.87 across country.

Correlations were usually high between evaluations for the same parity across countries $(0.84$ to 0.96$)$ even though based on different daughters. Genetic correlations for Holstein bull evaluations for milk yield estimated by Interbull (2006b) are relatively high (0.91 to 0.95) among Canada, the Netherlands, and the United States compared with those among most other countries that participate in Interbull. However, Interbull groups countries by grazing system and by climate and then limits correlation estimates to 0.85 to 0.98 for countries in the same group and 0.75 to 0.90 for countries in different groups (Interbull Centre, 2004).

Correlations between parity-specific evaluations were higher on average for Canada and the Netherlands than for the United States: 0.02 higher for Canada and 0.03 for the Netherlands for bulls with $\geq 500$ daughters and 0.13 higher for both Canada and the Netherlands for bulls with $\geq 50$ daughters. The higher correlations probably resulted partly because the genetic covariance matrices in the Canadian and Dutch test-day models include estimated correlations among parities (Schaeffer et al., 2000; De Roos et al., 2001). Those estimated correlations are 0.81 for Canada and 0.85 for the Netherlands between parities 1 and 2; 0.73 and 0.80 , respectively, between parities 1 and 3 ; and 0.88 and 0.87 , respectively, between parities 2 and 3 (Interbull, 2006a). Correlations between Canadian and Dutch parity-specific evaluations within country (Table 2) were considerably higher than correlations estimated in the evaluation models. 


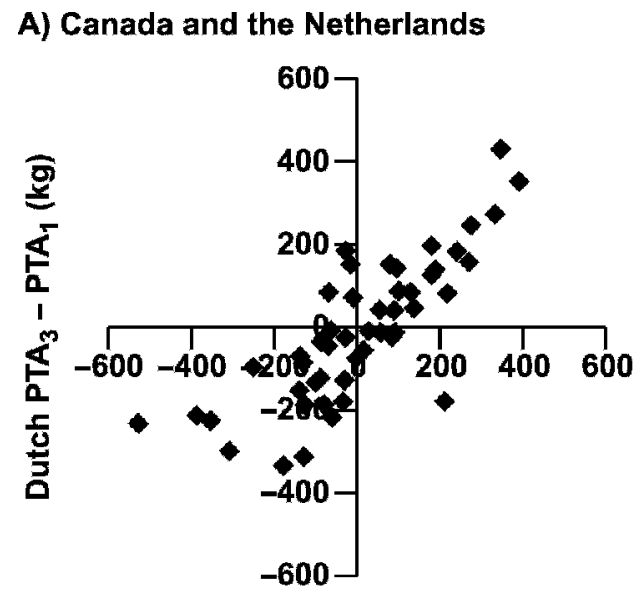

Canadian PTA 3 - PTA $(\mathbf{k g})$

B) Canada and the United States

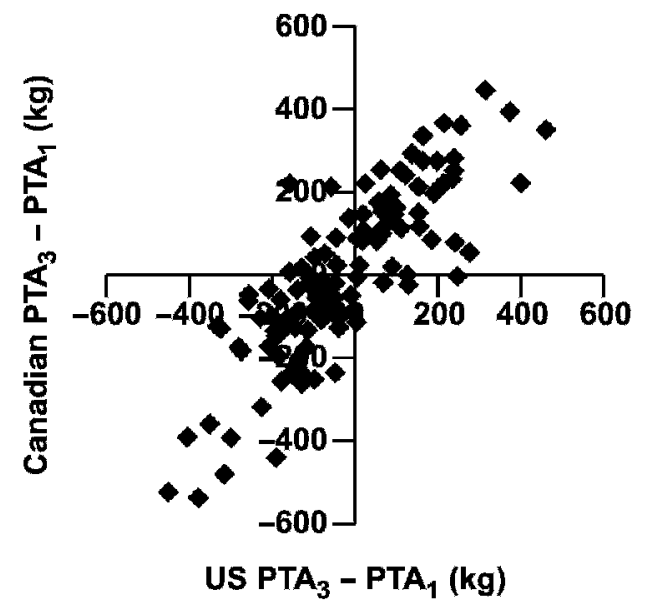

C) The Netherlands and the United States

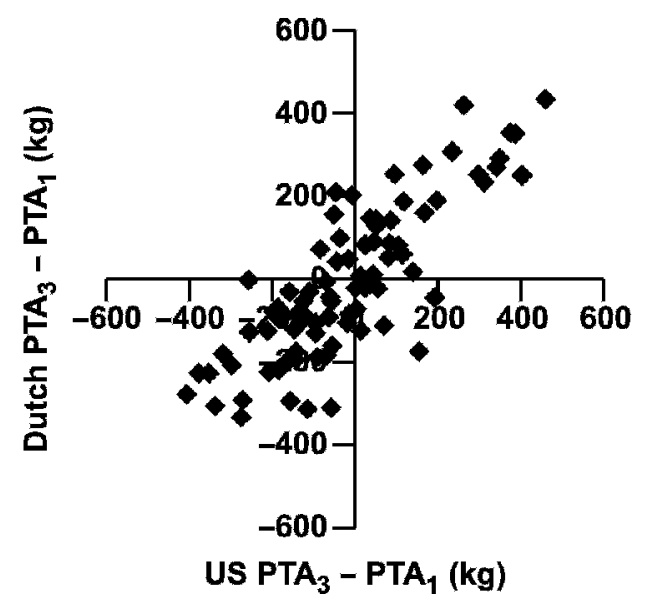

Figure 2. Scatter plots of differences between PTA for parities 1 and 3 for bulls with $\geq 500$ daughters in both countries for A) Canada and the Netherlands, B) Canada and the United States, and C) the Netherlands and the United States.
To allow comparison across countries of individual bull differences between parity-specific evaluations, Canadian and Dutch EBV were converted to PTA. Figure 1 shows individual differences for bulls with $\geq 500$ daughters between PTA for parities 1 and 2 compared with differences between PTA for parities 1 and 3 for Canada, the Netherlands, and the United States. Regression estimates and their standard errors were 1.02 \pm 0.03 for Canada, $1.16 \pm 0.03$ for the Netherlands, and $1.00 \pm 0.01$ for the United States. Most of the bulls that deviated appreciably from the population mean for daughter maturity rate (as evidenced by differences between PTA for parities 1 and 3) had already indicated that tendency in PTA for parity 2 . Only the regression estimate for the Netherlands suggested additional change in the daughter maturity rate in the same direction after parity 2 . Knowledge of those relationships is important in determining how to model maturity rate in genetic evaluations.

Correlations among Canada, the Netherlands, and the United States for differences in parity-specific evaluations within country are given in Table 3 for bulls with $\geq 50$ and $\geq 500$ daughters. For bulls with $\geq 50$ daughters, correlations for evaluation differences between parities 1 and 2 and between parities 1 and 3 were intermediate ( 0.61 to 0.72$)$. Correlations for evaluation differences between parities 2 and 3 were much lower (0.18 to 0.29). Corresponding correlations between countries were higher for bulls with $\geq 500$ daughters: 0.82 to 0.89 for evaluation differences between parities 1 and 2, 0.79 to 0.84 between parities 1 and 3, and 0.55 to 0.70 between parities 2 and 3. Parity-specific evaluations that were most correlated within and across country (Table 2) had the lowest correlations between countries for their differences within country. The across-country relationship of evaluation differences for parities 2 and 3 was low, most likely because evaluations for parities 2 and 3 are closely related. Prediction of differences in milk yield between parities (a measure of maturity rate) requires more daughters to obtain accuracy equal to that for single-parity evaluation.

Figure 2 shows individual differences for bulls with $\geq 500$ daughters in both countries between PTA for parities 1 and 3 by country pairs. Differences between countries were consistent, which indicates that genetic differences in daughter maturity rate are real. Regression estimates near 1.0 seem desirable because that would reflect uniformity in maturity rate across countries, but there is no obvious reason why regressing one country on another would be preferable to the reciprocal. Only 1 of the 3 regression estimates ( 0.71 to 0.91 ) illustrated in Figure 2 deviated significantly from 1.0, having standard errors ranging from 0.05 to 0.08 . 
Table 4. Coefficients (b) within birth year and country and SE for regression of son on sire for parityspecific and official overall evaluations for milk yield and for difference in parity-specific evaluations for sires with $\geq 500$ daughters and sons with $\geq 50$ daughters in Canada, the Netherlands, and the United States

\begin{tabular}{|c|c|c|c|c|c|c|}
\hline \multirow[b]{2}{*}{ Evaluation } & \multicolumn{2}{|c|}{$\begin{array}{c}\text { Canada } \\
(3,699 \text { sire-son pairs }) \\
\end{array}$} & \multicolumn{2}{|c|}{$\begin{array}{c}\text { The Netherlands } \\
(2,500 \text { sire-son pairs })\end{array}$} & \multicolumn{2}{|c|}{$\begin{array}{c}\text { United States } \\
(12,962 \text { sire-son pairs })\end{array}$} \\
\hline & $\mathrm{b}$ & $\mathrm{SE}$ & $\mathrm{b}$ & $\mathrm{SE}$ & $\mathrm{b}$ & $\mathrm{SE}$ \\
\hline Parity 1 & 0.51 & 0.03 & 0.46 & 0.03 & 0.44 & 0.01 \\
\hline Parity 2 & 0.53 & 0.02 & 0.48 & 0.03 & 0.43 & 0.01 \\
\hline Parity 3 & 0.53 & 0.02 & 0.50 & 0.03 & 0.44 & 0.02 \\
\hline Parity 2 - parity 1 & 0.46 & 0.02 & 0.44 & 0.03 & 0.42 & 0.01 \\
\hline Parity 3 - parity 1 & 0.46 & 0.02 & 0.43 & 0.03 & 0.46 & 0.01 \\
\hline Parity 3 - parity 2 & 0.45 & 0.03 & 0.35 & 0.04 & 0.47 & 0.04 \\
\hline Official overall $^{1}$ & 0.53 & 0.02 & 0.49 & 0.03 & 0.44 & 0.01 \\
\hline
\end{tabular}

${ }^{1}$ Official overall evaluation dates were November 2004 for Canada, August 2005 for the Netherlands, and August 2005 for the United States.

\section{Maturity Effects Across Generations}

Regression coefficients for son on sire (Table 4) were near the expectation of slightly less than 0.50 for parityspecific evaluations within country: 0.52 for Canada, 0.48 for the Netherlands, and 0.44 for the United States. Regression coefficients for differences between parityspecific evaluations within country (Table 4) were similar and averaged 0.46 for Canada, 0.41 for the Netherlands, and 0.45 for the United States. Standard errors for all regression coefficients were small (0.01 to 0.04$)$.

\section{CONCLUSIONS}

Correlations among parity-specific genetic evaluations from Canada, the Netherlands, and the United States were high and generally increased as the number of daughters increased. As expected, correlations were higher between parities 2 and 3 than among other parities. A multiparity evaluation model, as implemented in Canada (Schaeffer et al., 2000) and the Netherlands (De Roos et al., 2001), produced higher correlations among parity estimates, particularly for bulls with few daughters. Differences in daughter maturity rate were highly correlated across countries and between sires and sons within each country. The consistent parity differences between bull evaluations provided convincing evidence that those differences were genetic. Modeling separate PTA for each parity should increase US evaluation accuracy and reduce evaluation oscillation for bulls with considerable change in the number of records per daughter, most noticeably for bulls with evaluations that have high reliability. Investigation of bull differences in maturity rate for fitness and health traits that are currently evaluated in most countries could be beneficial in improving evaluation accuracy for those traits.

\section{ACKNOWLEDGMENTS}

The cooperation of AgriTech Analytics (Visalia, CA), AgSource Cooperative Services (Verona, WI), Dairy Records Management Systems (Raleigh, NC), DHI Computing Services (Provo, UT), Texas DHIA (College Station, TX), and Holstein Association USA (Brattleboro, VT) in supplying yield and pedigree data through the National Genetic Improvement Program for calculation of USDA-DHIA genetic evaluations is acknowledged. The assistance of J. H. Megonigal Jr. and L. M. Walton (Animal Improvement Programs Laboratory, Beltsville, $\mathrm{MD}$ ) in calculating parity evaluations and of S. M. Hubbard (Animal Improvement Programs Laboratory) and others in manuscript review is greatly appreciated.

\section{REFERENCES}

Abdallah, J. M., and B. T. McDaniel. 2002. Heritability of changes in genetic evaluations of dairy bulls from first to later records of daughters. J. Dairy Sci. 85:951-957.

Animal Improvement Programs Laboratory. 2005. USDA yield evaluation description (Feb 2005). http://aipl.arsusda.gov/reference/ yield.htm Accessed Dec. 6, 2006.

Cassell, B. G., B. T. McDaniel, and H. D. Norman. 1983. Modified contemporary comparison sire evaluations from first, all, and later lactations. J. Dairy Sci. 66:140-147.

De Roos, A. P. W., A. G. F. Harbers, and G. de Jong. 2001. Random regression test-day model in The Netherlands. Interbull Bull. 27:155-158.

Henderson, C. R., O. Kempthorne, S. R. Searle, and C. M. von Krosigk. 1959. The estimation of environmental and genetic trends from records subject to culling. Biometrics 15:192-218.

Interbull Centre. 2004. Genetic correlation estimation procedure. http://www.interbull.org/documents/genetic_correlation_ estimation_procedure_042t.pdf Accessed Dec. 13, 2006.

Interbull (International Bull Evaluation Service). 2006a. Description of National Genetic Evaluation Systems for dairy cattle traits as applied in different Interbull member countries. http:// www-interbull.slu.se/national_ges_info2/begin-ges.html Accessed Nov. 28, 2006.

Interbull (International Bull Evaluation Service). 2006b. Interbull routine genetic evaluation for dairy production traits, November 2006. http://www-interbull.slu.se/eval/nov06.html Accessed Nov. $28,2006$. 
Jorjani, H. 2006. International genetic evaluation for female fertility traits. Interbull Bull. 34:57-64.

Keown, J. F., H. D. Norman, and R. L. Powell. 1976. Effects of selection bias on sire evaluation procedures. J. Dairy Sci. 59:18081816.

Norman, H. D., J. L. Hutchison, J. R. Wright, M. T. Kuhn, and T. J. Lawlor. 2007. Selection on yield and fitness traits when culling Holsteins during the first three lactations. J. Dairy Sci. 90:1008-1020.

Norman, H. D., R. L. Powell, J. R. Wright, and P. M. VanRaden. 2004. Genetic relationships of milk yield for different parities between bulls and their sons. J. Dairy Sci. 87(Suppl. 1):413. (Abstr.)

Norman, H. D., J. R. Wright, R. L. Powell, and P. M. VanRaden. 2005. Impact of maturity rate of daughters on genetic ranking of Holstein bulls. J. Dairy Sci. 88:3337-3345.

NRS (Nederlands Rundvee Syndicaat). 2005. Breeding value estimation of milk production traits with test-day model. Chapter E-7, Handbook NRS. NRS, Arnhem, the Netherlands.
Schaeffer, L. R., J. Jamrozik, G. J. Kistemaker, and B. J. Van Doormaal. 2000. Experience with a test-day model. J. Dairy Sci. 83:1135-1144.

Strandberg, E. 1991. Breeding for lifetime performance in dairy cattle. Ph.D. Thesis. Swedish University of Agricultural Sciences, Uppsala, Sweden.

Sullivan, P. G. 2000. Options to evaluate sires for multiple traits in multiple countries. Interbull Bull. 25:13-17.

VanRaden, P. M. 1997. Lactation yields and accuracies computed from test day yields and (co)variances by best prediction. J. Dairy Sci. 80:3015-3022.

Wiggans, G. R., and P. M. VanRaden. 1989. USDA-DHIA animal model genetic evaluations. Natl. Coop. DHI Progr. Handbook, Fact Sheet H-2. Ext. Serv., USDA, Washington, DC.

Wiggans, G. R., and P. M. VanRaden. 2004. Accounting for differences in rate of maturity in yield evaluations. J. Dairy Sci. 87(Suppl. 1):412. (Abstr.) 